\title{
EVALUATION OF ENDOTOXEMIA, SOLUBLE CD14 AND IL-1B IN DOGS WITH INTESTINAL DYSBIOSIS THAT WERE TREATED WITH PROBIOTICS: A PROSPECTIVE STUDY
}

\author{
MARIA-CĂTĂLINA MATEI ${ }^{1}$, SANDA ANDREI ${ }^{1}$, VICTORIA BUZA ${ }^{1}$, MIHAI CERNEA ${ }^{1 *}$, DARIA \\ ANTONIA DUMITRAS ${ }^{1}$, DANIELA NEAGU ${ }^{1}$, HORAȚIU RAFA ${ }^{1}$, CRISTIAN PAUL POPOVICI ${ }^{1}$,

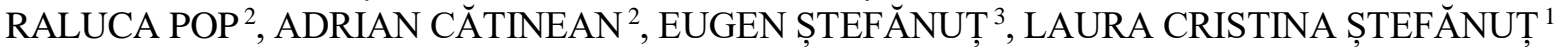 \\ ${ }^{1}$ Faculty of Veterinary Medicine, University of Agricultural Sciences and Veterinary Medicine of Cluj-Napoca, Romania \\ 2 "Iuliu Hatieganu" University of Medicine and Pharmacy, Cluj-Napoca, Romania \\ ${ }^{3}$ EST Research, Bucharest, Romania
}

*corresponding author: mihai.cernea@usamvcluj.ro

\begin{abstract}
The aim of this study was to compare the serum endotoxin levels in correlation with soluble CD14 and IL-1 $\beta$ in dogs with intestinal dysbiosis that were treated with a probiotic product containing Bacillus subtilis, Bacillus licheniformis and Pediococcus acidilactici. Levels of serum endotoxin, soluble CD14 and IL-1 $\beta$ were assessed before meal consumption, and 6 and $12 \mathrm{~h}$ after meal consumption, both prior to initiation of probiotic treatment and after completion of 30 days of treatment. Pre-meal serum endotoxin levels decreased by $25.89 \%$ and $6 \mathrm{~h}$ and $12 \mathrm{~h}$ post-meal levels decreased by $35.00 \%$ and $44.93 \%$, respectively, when compared to the respective pre-treatment values which correlated with a decrease in serum soluble CD14 levels, while IL-1 $\beta$ remained approximatively constant.
\end{abstract}

\section{Rezumat}

Scopul prezentului studiu a fost de a compara nivelul seric de endotoxine, corelat cu CD14 solubil și IL1- $\beta$, la câini cu disbioză intestinală tratați cu un produs probiotic ce conține Bacillus subtilis, Bacillus licheniformis și Pediococcus acidilactici. Nivelurile de endotoxină serică, CD14 solubil și IL1- $\beta$ au fost determinate înainte de hrănire, la 6 și respectiv 12 ore după masă, atât înainte de inițierea tratamentului cu probiotic, cât și la finalizarea celor 30 de zile de tratament. Comparând rezultatele post-tratament cu cele obținute înaintea administrării probioticului, nivelul ante-prandial al endotoxinei serice a scăzut cu $25,89 \%$, iar la 6 ore și 12 ore scăderea a fost de $35,00 \%$, respectiv $44,93 \%$. Reducerea endotoxinei serice poate fi corelată cu tendinţa de scădere a nivelului CD14 solubil, în timp ce nivelul IL1- $\beta$ a rămas aproximativ constant.

Keywords: metabolic endotoxemia, intestinal dysbiosis, probiotic, CD14, IL-1 $\beta$, dogs

\section{Introduction}

The gastrointestinal (GI) microbiome can be defined as a complex group of organisms that includes bacteria, archaebacteria, fungi, protozoa and viruses $[1,11,13$, 14]. These organisms comprise an ecosystem that is able to colonize the GI tracts of all animals. Substantial scientific data support the microbiome involvement in many vital physiological processes of host, such as maintenance of homeostasis, metabolic processes and immunological defence. Together, these vital roles make the microbiome an important and active foundation for the physiological activities of the host $[1,12]$. During the life of an animal, the GI microbiome is subject to different factors which can result in composition changes. For this reason, the GI microbiome is considered to be a dynamic entity, able to adapt to influencing factors such as diet, environment, diseases or medical interventions [1].

Although the GI microbiome is able to adapt to some changes in the host, other changes in microbiome structure are linked to alterations in homeostasis that can, in some cases, be associated with disease. Disorders such as inflammatory bowel disease, asthma, metabolic syndromes and immune mediated diseases are correlated with changes in the microbiome composition [1]. A disruption in the homeostasis of the GI microbiome is defined as dysbiosis, which is characterized by a decrease in the quantity and richness of the bacteria component of the microbiome [12]. This may be followed by intestinal and systemic changes that result in inflammation. Dysbiosis does not always imply the presence of pathogenic bacteria; the absence of important commensals is considered to be as harmful as the presence of pathogenic bacteria [1, 12].

Moreover, there is a link between intestinal dysbiosis, inflammatory status of the intestine and a systemic condition called metabolic endotoxemia. Metabolic endotoxemia is a condition characterized by a substantial increase in serum endotoxins in the first hours following consumption of a meal. Among these endotoxins, lipo- 
polysaccharides (LPSs) are most commonly identified. Currently, a diet high in fat and, consequently, high in calories has a higher impact on endotoxemia levels than a low fat diet [6].

In order to demonstrate an increase in the concentration of serum endotoxins, specific inflammatory markers such as interleukin (IL)-6, IL-1 $\alpha$, interferon (IFN) $\gamma$, triglycerides and insulin can be measured [6].

There is a strong correlation between chronic metabolic endotoxemia and associated inflammation. This association is thought to increase the risk of developing a variety of chronic diseases. Currently, there are data available that suggest that diseases such as diabetes, obesity, anxiety, depression and cardiovascular disease have metabolic endotoxemia as a component of their ethology [6].

The main mechanism of action of metabolic endotoxemia is considered to be based on an innate immune response that produces a minor, subclinical but persistent inflammation that is stimulated by circulating endotoxins. The most common and rapidly increased endotoxin molecules are LPSs. LPS is also a major component of the external cell membrane of the Gram-negative bacteria. This is of particular importance because it is known that the digestive tract is predominantly colonized by Gram-negative bacteria. In other words, the commensal bacteria in the GI tract are the primary origin of the endotoxins (LPS) and, consequently, of the intestinal inflammation. Due to this link between the resident bacterial populations and endotoxemia, the health and composition of the intestinal microbiota becomes a very important aspect of chronic endotoxemia. Although the persistent inflammation is minor and subclinical, it is significant due to the suppressive mechanism exerted on the host immune system [6].

Given the strong connection between the composition of the GI microbiome and the health of the host, methods for re-establishing the normal composition of the intestinal microbiome should be investigated. Even if antibiotics are used in the gastroenterological problems, in the present context of the antibioresistance due to an irrational usage $[3,8]$, another possible method is the use of probiotics, which are made from "good" bacteria that are able to colonize the intestinal tract and/or reset a healthy homeostasis in dysbiosed bacterial communities [14].

Probiotics are an effective prophylactic treatment for GI diseases [4]. They are able to compete for nutrients with pathogenic bacteria, binding sites in the intestine and, consequently, may inhibit the development of pathogenics. They also stimulate the host immune system, produce antimicrobial substances and acidify the intestinal environment [4]. In veterinary medicine, the most commonly used genera for probiotic formulations are Lactobacillus spp. and Bifidobacterium spp. In the last few years, Bacillus spp. have gained attention due to their ability to sporulate, a characteristic which makes them more resistant to both the acidic $\mathrm{pH}$ of the GI tract and to environmental stress [4].

Our study aimed to investigate the connection between endotoxemia levels and the intestinal microbial health/ disease status, and to establish whether the probiotic product FidoSpore ${ }^{\circledR}$, Microbiome Labs, LLC (Bacillus subtilis HU 58, Bacillus licheniformis SL 307 and Pediococcus acidilactici) can diminish endotoxemia levels in dogs with apparent dysbiosis in veterinary clinical practice.

\section{Materials and Methods}

\section{Study design}

A total of six adult dogs, aged between 7 months and 5 years and 9 months, were entered into the study between 10 April and 29 July 2019. The dogs were treated with a probiotic product (FidoSpore ${ }^{\circledR}$ supplied by Microbiome Labs, LLC) containing B. subtilis HV 58 strain, B. licheniformis SL 307 and $P$. acidilactici. The probiotic was administrated at meal once a day 30 days.

On days 0 and 31 of the study, each dog was given a clinical exam, during which blood samples were obtained at multiple time points using standard venipuncture. For assessment of serum immune and inflammatory parameters and the detection of endotoxemia, blood was collected in a fasting state $(12 \mathrm{~h}$ after meal consumption), dogs were then fed and blood was again collected $6 \mathrm{~h}$ and $12 \mathrm{~h}$ later.

Between days 1 and 30 of the study, the probiotic product was administered to the animals with their meal and according to the manufacture recommendations. Bioethics Committee Approval

This study was conducted between April and July 2019 at the University of Agricultural Sciences and Veterinary Medicine of Cluj-Napoca, Romania. No harm was caused to the enrolled animals as a result of this study. Each individual dog was enrolled in the study after the owner was fully informed of the procedures involved and signed informed consent was obtained.

Study population

This study was based on real clinical cases (Table I) of dogs that were brought into the clinic for treatment of GI manifestations. Dogs presenting with intestinal dysbiosis were considered for inclusion in the study if they met the study criteria. Inclusion criteria were antibiotic treatment (minimum duration of 2 weeks) or a recent history of gastroenterological manifestations (diarrhoea, vomiting) and normal consumption of one meal per day. Dogs were excluded if they had acute liver or kidney disease, or if they had intestinal parasites. There were no lifestyle or nutrition changes for the dogs, and they remained in the care of their owner for the duration of the study. 
Baseline characteristics of the study dogs

\begin{tabular}{|c|c|c|c|c|}
\hline Patient code & Breed & Age & Sex & Observations, diagnosis, treatment \\
\hline 09-B & Labrador & 7 months & male & recurrent diarrhoea, vomiting \\
\hline 10-Y & Akita Inu & 5 years and 9 months & female & diarrhoea, chronic pancreatitis \\
\hline 11-L & Labrador & 4 years & male & $\begin{array}{c}\text { dermatitis, antibiotic treatment } \\
\text { (enrofloxacin) 14 days }\end{array}$ \\
\hline 12-D & Boxer & 2 years & male & recurrent diarrhoea induced by stress \\
\hline 13-U & Bucovina Shepherd & 4 years and 5 months & male & recurrent diarrhoea \\
\hline 14-M & Swiss White Shepherd & 3 years & male (castrated) & recurrent diarrhoea \\
\hline
\end{tabular}

\section{Treatment}

The probiotic product (FidoSpore ${ }^{\circledR}$ supplied by Microbiome Labs, LLC) tested was composed of three bacterial strains: B. subtilis HU58, B. licheniformis SL307 and $P$. acidilactici. The probiotic product was given in capsules. One capsule per day was administered to each dog with their daily meal for 30 days. Liver powder was used to improve the taste of the probiotic product and to ensure it was ingested.

Determination of endotoxemia

To assay for endotoxemia, we used the ToxinSensor ${ }^{\mathrm{TM}}$ Chromogenic LAL Endotoxin Assay Kit (GenScript, Piscataway, NJ, USA). This method utilizes a modified Limulus Amebocyte Lysate and a synthetic colour producing substrate to detect endotoxin chromogenically. The end product can be measured using a spectrophotometer $(\lambda=545 \mathrm{~nm})$ and the concentration of endotoxin in the test samples can be determined by comparing to a standard curve. The kit has a minimum endotoxin detection limit of $0.01 \mathrm{EU} / \mathrm{mL}$ and a measurable concentration range of 0.01 to $1 \mathrm{EU} / \mathrm{mL}$. The serum was assayed using three dilutions: undiluted, 1:1 and 1:2. Endotoxin levels were calculated for the serum samples diluted 1:2 using the standard curve $\left(\mathrm{R}^{2}=0.9808\right)$ generated in the assay.

Measurement of immune and inflammatory proteins IL-1 $\beta$ and soluble CD14 (sCD14) was assayed in the serum of all study dogs. The serum and timepoints tested in these assays were the same used for the assessment of endotoxemia.

IL- $1 \beta$ was measured using a canine IL- $1 \beta$ ELISA kit (Elabscience ${ }^{\circledR}$, Houston, Texas, USA); the concentration of IL-1 $\beta$ in each sample was calculated using the standard curve $\left(R^{2}=0.9527\right)$ generated in the assay.
sCD14 was assayed using a canine CD14 ELISA kit (Nori Canine $^{\circledR}$, Genorise Scientific Inc., Philadelphia, PA, USA). Serum sCD14 concentrations were calculated using the standard curve $\left(R^{2}=0.991\right)$ generated in the assay.

Statistical analysis

Data were analysed using a conditional analysis of variance (ANOVA) and the following conditions: dogs with dysbiosis $\times$ experiment time (day 0 , pre-probiotic administration; day 31 , post-probiotic administration (once daily for 30 days)) $\times$ meal time (pre-meal, $6 \mathrm{~h}$ post-meal, $12 \mathrm{~h}$ post-meal). Significance was set at $p<0.05$, which was determined using the StudentNewman-Keuls Multiple Comparisons Test. For evaluation of correlations, we used the Pearson (Pearson r) Correlation Test with the expression of correlation coefficient ( $r$ ) and coefficient of determination $\left(\mathrm{R}^{2}\right)$.

\section{Results and Discussion}

Clinical examination of the study dogs revealed diarrhoea, vomiting and/or skin lesions, depending on the reason for inclusion in the study. After probiotic treatment, we observed a decrease (3/6 patients: $10-\mathrm{Y}$, 11-L, 13-U) and/or disappearance (3/6 patients: 09-B, 12-D, 14-M) of digestive problems. Improvement in the general condition of the dogs was observed (compared with the general condition at day 0 ).

A comparison of endotoxemia levels pre- and postprobiotic treatment indicated a decrease in the level of endotoxemia detected in day 31 serum samples compared with day 0 samples (Table II; Figure 1).

Serum endotoxin, soluble CD14 and IL-1 $\beta$ response pre- and post-probiotic administration

\begin{tabular}{|c|c|c|c|c|c|c|}
\hline \multirow[t]{3}{*}{ Parameter } & \multicolumn{3}{|c|}{ Pre-probiotic administration (day 0) } & \multicolumn{3}{|c|}{ Post-probiotic administration (day 31) } \\
\hline & \multirow[t]{2}{*}{ Pre-meal } & \multicolumn{2}{|c|}{ Post-meal } & \multirow[t]{2}{*}{ Pre-meal } & \multicolumn{2}{|c|}{ Post-meal } \\
\hline & & $6 \mathrm{~h}$ & $12 \mathrm{~h}$ & & $6 \mathrm{~h}$ & $12 \mathrm{~h}$ \\
\hline $\begin{array}{l}\text { Endotoxemia } \\
(\mathrm{EU} / \mathrm{mL})\end{array}$ & $0.2958 \pm 0.168$ & $0.2880 \pm 0.200$ & $0.2713 \pm 0.170$ & $0.2192 \pm 0.241$ & $0.1872 \pm 0.145$ & $0.1494 \pm 0.070$ \\
\hline $\begin{array}{l}\text { soluble CD14 } \\
(\mathrm{pg} / \mathrm{mL})\end{array}$ & $23.6028 \pm 6.99$ & $23.2065 \pm 7.275$ & $23.3054 \pm 6.011$ & $21.1645 \pm 2.110$ & $20.5592 \pm 0.993$ & $20.7246 \pm 1.1389$ \\
\hline $\mathrm{IL}-1 \beta(\mathrm{ng} / \mathrm{mL})$ & $0.0447 \pm 0.015$ & $0.0410 \pm 0.014$ & $0.0486 \pm 0.015$ & $0.0410 \pm 0.009$ & $0.0458 \pm 0.007$ & $0.0453 \pm 0.010$ \\
\hline
\end{tabular}

Average percent differences (day $31 v s$. day 0) in serum endotoxin levels were $25.89 \%, 35.00 \%$ and $44.93 \%$ for pre-meal, $6 \mathrm{~h}$ post-meal and $12 \mathrm{~h}$ post-meal serum samples. The trend of decreased endotoxemia at day 31 ( $v s$. day 0) had significant progressive dynamics $\left(\mathrm{R}^{2}=0.9536\right)$ (Figure 1$)$. This indicated a 
significant improvement in intestinal conditions and correlated with the improvement in clinical diagnosis. Regarding the changes in sCD14 levels, we observed a trend of decreasing levels after completion of probiotic treatment, which was directly correlated with endotoxin levels (Table II; Figure 2). The correlation

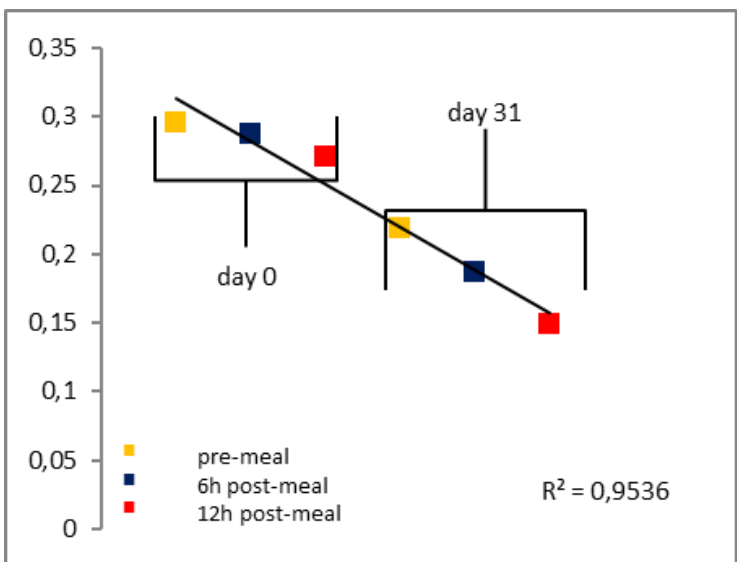

Figure 1.

Dynamic of the average and trend line of the endotoxemia $(\mathrm{EU} / \mathrm{mL})$ between the pre- and post-probiotic administration for the pre-meal measurements was statistically significant $\left(\mathrm{P}=0.05\right.$; correlation coefficient, $\mathrm{r}=0.8445$ and $\mathrm{R}^{2}=$ $0.744)$.

IL-1 $\beta$ levels remained relatively constant throughout the study (Table II; Figure 3).

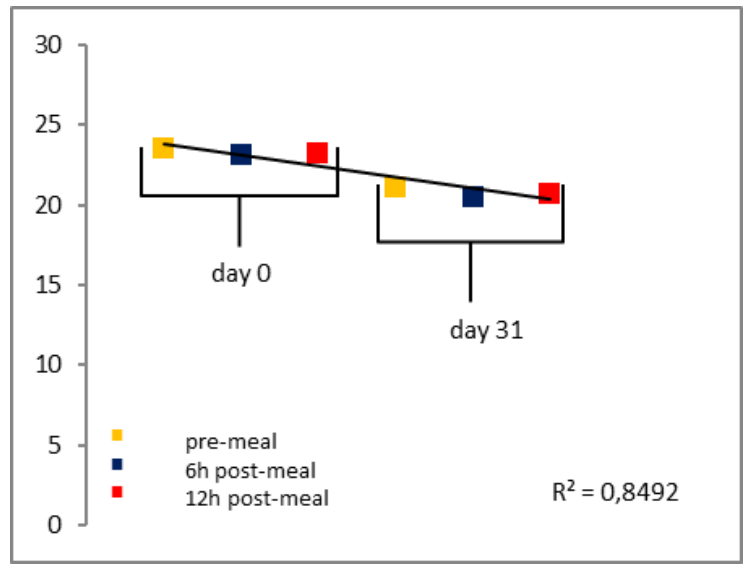

Figure 2.

Dynamic of the average and trend line of sCD14 $(\mathrm{pg} / \mathrm{mL})$

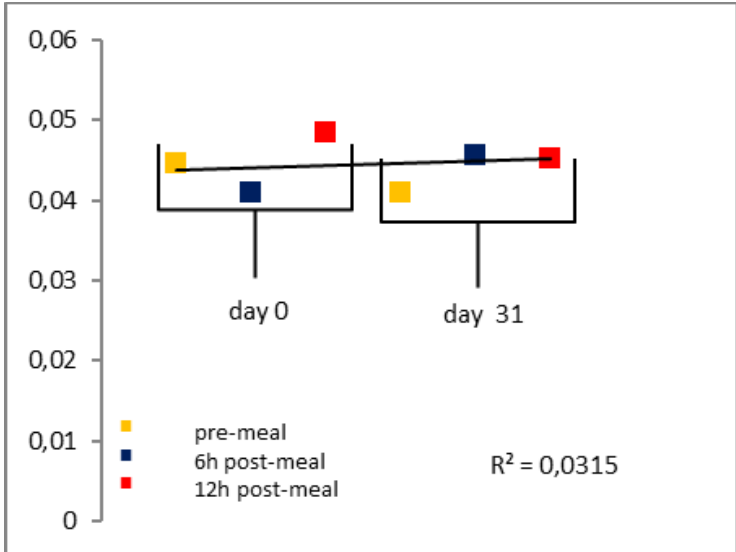

Figure 3.

Dynamic of the average and trend line of IL-1 $1 \beta(\mathrm{ng} / \mathrm{mL})$

Endotoxemia is a condition which is not well studied in the veterinary medicine. Most of the presently available data are extrapolated from human medicine [6]. The present study demonstrated that endotoxemia was strongly correlated with inflammatory status in dogs, which is also observed in humans [5]. From the little data available on dogs, we know that a small amount of endotoxin is able to produce inflammation [2].

Despite the close proximity between luminal bacteria and mucosal macrophages in the intestine, there is minimal inflammation under normal conditions. CD14 is a surface receptor found on macrophages; it facilitates interactions between macrophages and bacteria and their products. SCD14 can have an indirect role in cell activation by promoting transfer of LPS to membranebound CD14 [4], so the sCD14 levels are increased as a response to an LPS challenge [9]. Thus, CD14 is involved in the response to LPS [10]. The role CD14 plays in the intestine and that of LPS in endotoxemia justifies the use of CD14 in terms of understanding metabolic endotoxemia. Our study shows a strong correlation between changes in endotoxin levels and changes in SCD14 levels, both before and after probiotic administration.

In our study, all the six dogs had clinical signs of dysbiosis. The levels of endotoxemia were higher at all the time points (pre-meal, $6 \mathrm{~h}$ post-meal and $12 \mathrm{~h}$ post-meal) before probiotic administration, compared with those reported after completion of 30 days of probiotic treatment; all six dogs showed clinical improvement in their general health after completing the probiotic treatment (vs. pre-treatment). We reported a $25.89 \%$ decrease (at day 31 compared with day 0 ) in 
endotoxin levels for the pre-meal timepoint, a $35.00 \%$ decrease at $6 \mathrm{~h}$ post-meal and a $44.93 \%$ decrease at $12 \mathrm{~h}$ post-meal. This trend towards decreased levels of endotoxemia after probiotic treatment suggest that probiotic treatment may have an impact for reestablishing homeostasis in the GI microbiome. In 2017, McFary et al. [7] conducted a study on humans to see whether 30 days oral spore-based probiotic supplementation could reduce dietary endotoxemia. They showed that, in humans, the level of endotoxin decreased by $42 \%$ after completion of probiotic treatment. The results obtained in the present study suggest a similar effect of probiotic treatment in dogs.

Moreover, it is known that metabolic endotoxemia is accompanied by mild inflammation in humans [6] and probably in dogs. Bartko et al. (2017) [2] conducted a study in 80 dogs (Beagles). The researchers induced endotoxemia in the dogs using a small amount of endotoxin and demonstrated that endotoxin exposure increased TNF $\alpha$ and IL-6, inducing a self-limiting systemic inflammatory response. In our group of dogs with clinical symptoms of dysbiosis, the levels of serum sCD14 were decreased after 30 days of probiotic treatment. Additionally, the trend of decreased sCD14, which is a marker linked to LPS activity, was strongly correlated with the trend of decreased endotoxin levels. These data may explain the mechanism of action for the link between CD14, LPS and intestinal inflammation. When LPS binds to CD14, the body responds by initiating an inflammatory immune response which results in the expression of $\mathrm{NF \kappa B}$. Activation of $\mathrm{NF \kappa B}$ leads to an increased expression of pro-inflammatory mediators including TNF $\beta$, IL-1 $\beta$, IL-6 and MCP-1 [6]. Considering the above information, a link between endotoxemia levels and changes in levels of sCD14 and inflammatory mediators is expected. In our study we assessed IL-1 $\beta$ as a marker for inflammatory mediators. Levels of serum IL-1 $\beta$ were measured before and after probiotic treatment and at the same time points used to measure endotoxin and sCD14. Although, we reported variations in endotoxin and sCD14 levels, the levels of IL- $1 \beta$ remained relatively constant. It should be noted that all of the currently available data regarding the mechanisms of action for metabolic endotoxemia were extrapolated from data obtained from human studies. In humans, after 30 days of spore-based probiotic supplementation, IL-1 $\beta$ levels were significantly reduced [7]. Given the fact that currently there are no similar data available for dogs and that our study reported no changes in IL$1 \beta$, it is likely that the correlation between the two markers may not be the same in humans and dogs.

\section{Conclusions}

The data obtained from this study provided information regarding metabolic endotoxemia in dogs with clinic signs of dysbiosis. We observed a positive correlation between the changes in serum endotoxin and sCD14 levels after probiotic treatment. Treatment with a probiotic product based on $B$. subtilis, B. licheniformis and $P$. acidilactici strains resulted in a notable improvement in the general health status of the dogs; additionally, we reported a substantial decrease in metabolic endotoxemia levels. Therefore, this bacterial combination can be considered an alternative treatment for the prevention and treatment of conditions linked to metabolic endotoxemia and intestinal dysbiosis in dogs.

\section{Acknowledgement}

This study was funded by MICROBIOME LABS PHYSICIANS EXCLUSIVE, LLC (Agreement no 30130, 18 December 2018).

\section{Conflict of interest}

The authors declare no conflict of interest.

\section{References}

1. Barko PC, Michael MA, Swanson KS, Williams DA, The gastrointestinal microbiome: a review. J Vet Intern Med., 2018; 32: 9-25.

2. Bartko J, Derhaschnig U, Neels T, Nabozny GH, Harcken C, Leuschner J, Vries FD, Jilma B, Selective glucocorticoid receptor modulation inhibits cytokine responses in a canine model of mild endotoxemia. Pharmacol Res., 2017; 125: 215-223.

3. Boboia A, Florea LS , Turcu-Stiolica A, Tăerel AE, Rais C, Revnic C, Florea A, Vedeanu NS, Nastasă $\mathrm{C}$, Oniga $\mathrm{O}$, Decision analysis of antibiotic use. Farmacia, 2020; 68(4): 757-765.

4. Felix AP, Netto MVT, Murakami FY, De Brito CBM, De Oliveira SG, Maiorka A, Digestibility and fecal characteristic of dogs fed with Bacillus subtilis in diet. Cienc Rural, 2010; 40(10): 2169- 2173.

5. Hailman E, Vasselon $\mathrm{T}$, Kelley M, Busse La HUMC, Lichenstein HS, Detmers PA, Wright SD, Stimulation of macrophages and neutrophils by complexes of lipopolysaccharide and soluble CD14. J Immunol., 1996; 156: 4384-4390.

6. Krishnan K. Metabolic endotoxemia, A driving force behind chronic illness. Aapi's nutrition guide to optimal health using principles of functional medicine \& nutritional genomics. 2017; Part III: 269-286.

7. McFarlin KB, Henning AL, Bownam EM, Melody AG, Carbajal KM, Oral spore-based probiotic supplementation was associated with reduced incidence of post-prandial dietary endotoxin, triglycerides, and disease risk biomarkers. World J Gastrointest Pathophysiol., 2017; 8: 117-126.

8. Neag MA, Bocșan IC, Vesa Ș, Goșa D, Cătinean A, Nagy G, Mircea PA, Buzoianu AD, The inadequate use of antibiotics in a gastroenterology department. Farmacia, 2019; 67(6): 1066-1070.

9. Schütt C, Schilling T, Grunwald U, Schönfeld W, Krüger C, Endotoxin-neutralizing capacity of soluble CD14. Res Immunol., 1992; 143: 71-78.

10. Smith PD, Lesley E, Smythies MMB, Sibley DA, Russell MW, Merger M, Sellers MT, Orenstein JM, 
FARMACIA, 2021, Vol. 69, 6

Shimada T, Graham MF, Kubagawa H, Intestinal Macrophages Lack CD14 and CD89 and Consequently Are Down-Regulated for LPS- and IgA-Mediated Activities. J Immunol., 2001; 167(5): 2651-2656.

11. Suchodolski JS, Morris EK, Allenspach K, Jergens AE, Harmoinen JA, Westermarck E, Steiner JRM, Prevalence and identification of fungal DNA in the small intestine of healthy dogs and dogs with chronic enteropathies. Vet Microbiol., 2008; 132: 379-388.

12. Suchodolski JS, Diagnosis and interpretation of intestinal dysbiosis in dogs and cats. Vet J., 2016; 215: 30- 37.
13. Truelstrup H, Allan-Wojtas PM, Jin YL, Paulson AT, Survival of Ca-aglutinate microencapsulated Bifidobacterium spp. in milk and simulated gastrointestinal conditions. Food Microbiol., 2002; 19: 35-45.

14. Ziese AL, Suchodolski JS, Hartmann K, Busch K, Anderson A, Sarwar F, Sindern N, Unterer S, Effect of probiotic treatment on the clinical course, intestinal microbiome, and toxigenic Clostridium perfringens in dogs with acute hemorrhagic diarrhea. PLOS ONE, 2018; 13(9): e0204691: 1-16 